\title{
An Autumn Walk
}

By Evelyn M. Casson, Carter, Sask.

Photos by Carmichael

ATHOUGH the sun was
shining there was a
hint of chill in the gentle
breeze that blew from the
north-east. As I walk alone
I see and hear signs of au-
tumn on all sides. There is
a profusion of goldenrod by
the roadside; blue asters
cluster nearby and the lacy
yarrow has grown quite tall.

In a nearby clump of poplars there is a flock of young crows which raise a hue and cry at my appearance; but they can't fool me-they are only youngsters, for their voices have a baby is h quaver as they loudly call "Caw! Caw!"

Going on down the trail I came to a deep hollow, well shaded by tall trees under which grew a thick bed of golden St. Johnswort, nodding on their tall slim stems. It was a lovely sight and $I$, at once remembered the lines of the poem "The Daffodils", ... .

"Ten thousand saw I at a glance,

Tossing their heads in sprightly dance."

The plants were up to twenty inches tall - the leaves smooth and growing in pairs up the stem. On the top were three or four bright yellow blooms, each having five petals with s h in y, golden-yellow stamens.

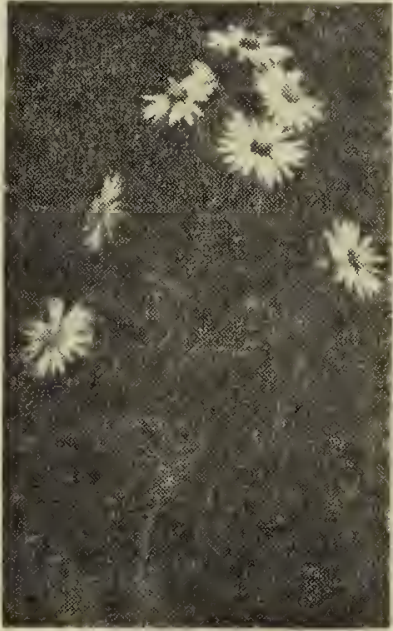

I walked on deeper into the woods. Suddenly I came to an open glade with large shade trees and no underbrush. There on all sides were dozens of those big mushrooms that spring up at this season of the year if the rainfall has been plentiful. There were all kinds and colors; big orange ones with tan flecks on them; flat cream-coloured ones; bright reddish-orange ones with round tops; white ones sha ped like a saucer; golden-brown ones with a spongy underside, tan ones shaped like a funnel and bright red ones that looked like gay Mexican sombreros. Everywhere I looked there were mushrooms piled above each other and some growing so close to the trees that they were splitting as they grew. On measuring the largest one I found it was ter inches across and eleven inches high. The y were a gay sight on this lovely fall day.

(Editor's note: Your find of St. John's-wort in Saskatchewan is an interesting one. I have never seen the plants growing here, 'but have collected specimens high in the mountains at Waterton Lake, Alberta. Four different species are reported from Manitoba. Yours may have been Hypericum ellipticum). 